\title{
The Comparative Study Between the Perceived Image and Projected Image: A Case of Beijing Wtown
}

\author{
Chang Ge \\ School of Management, Shanghai University, Shanghai, China \\ Email: 15736874019@163.com
}

\begin{abstract}
Taking Beijing Wtown as an example, this paper aims to measure and analyses the differences between the two sides of the tourist destination image (demand-side perceived vs. supply-side projected). The study finds that the tourist destination image of Beijing Wtown can be divided into three themes: tourism attractions, tourism infrastructure and tourism environment. The study identified several important differences between the perceived and projected tourist destination image. And the results offered valuable advises for future marketing strategies in Beijing Wtown.
\end{abstract}

Keywords: Small tourism town, perceived image, projected image, Beijing Wtown

\section{Introduction}

The small tourism town is a special product of China's urbanization development to a specific stage, and it is a new exploration of the country to promote new urbanization and coordinated urban and rural development. In July 2016, The Circular on Developing the Small Tourism Town issued by the government proposed to cultivate about 1,000 small tourism town by 2020 . With the publication of the lists of small tourism towns by the ministry of housing and urban-Rural development, small tourism towns have become the hotpot of urbanization in China. Among the list of 276 small tourism towns in July 2017, 118 small tourism towns dominated by tourism industry play an important role in promoting the process of urbanization in China (Zhao Hua, 2017). Therefore, in the historical trend of new urbanization construction, how to promote the development of small tourism towns with good and fast development has been widely concerned.

In the face of the construction boom, many regions follow the trend to set up small tourism towns, and blindly apply the development model of small tourism towns in developed areas. Whether these towns are really as special as the destination marketing organizations said? Whether the perceived images by tourists are consistent with the information projected by the destination itself? These problems are being paid more and more attention to. Therefore, taking Beijing Wtown as an example, this paper's objectives were to examine the perceived image by visitors to Beijing Wtown and projected image by destination marketing organizations. The two images were then compared in order to draw conclusions for future marketing strategies.

\section{$2 \quad$ Literature Review}

\subsection{Small Tourism Town}

At present, there is no clear definition of small tourism town. Most scholars agree that tourism town is not an administrative town, but a relatively independent area on the space dominated by tourism industry. It can be either a structured town or a market town, or a large-scale tourism real estate project or the traditional village with ornamental value and cultural connotation, which has some tourism facilities such as hotel and resorts, shopping mall and entertainment (Yang Liguo, Liu Qiang and LI Qiang, 2017).

\subsection{Perceived Tourist Destination Image}

For many decades, tourist destination image (TDI) has been current subject of study in the literature of travel, tourism and hospitality (Chon, K.-S., 1990; Li, J. et al., 2015). Foreign scholars started to study 
perceived TDI earlier, and the core words that have been used to define its nature are, in order of frequency: impression, perception, belief, idea, representation, and feeling. The perception of visitors refers to tourists' impression, understanding and comprehensive evaluation of destination (Wu Xiaogen, Du Yingying, 2011). Various methodologies of measuring destination image have been developed over the past 30 years, most of which consist of either a structured, quantitative approach or, less frequently, an unstructured, qualitative approach (Pike, S., 2002). Structured approach is used to study the influence factors of tourists' perception, the formation mechanism of perception, the measurement and evaluation of perception, etc. Studies employing structured method usually need lots of sample which obtained by questionnaire survey. Researchers measured the perceived image by factor analysis and regression analysis base on the sample (Zang Dexia, Huang Jie, 2007). The alternatives to structured approaches are unstructured, qualitative methods of measurement such as focus groups or open-ended survey questions with content analysis and various sorting techniques, employing free form descriptions to capture the more holistic components of the image (Echtner, C. M., \& Ritchie, J. R. B., 1991). In recent years, many scholars used the unstructured method to obtain the image perceived by visitors based on user-generated content (UGC) such as tourists' travel notes shown on blogs, Weibo or OTA.

\subsection{Projected Tourist Destination Image}

Projected image are created and projected by destination marketing organizations (Liu Huan, 2015). Compared with the research on perceived image, the related research on projected image started late. Numerous studies document the efforts of destination marketing organizations in researching, building, promoting, evaluating, and maintaining destination image. For a long time, destination imagery was controlled almost exclusively by a destination's marketing organizations. Materials produced by destination marketing organizations include brochures, guidebooks, postcards, video commercials, and most recently, destination websites and other online materials. The methods of measuring projected image also include both structured and unstructured methods. Employing structured method, Grosspiets (2006) researched Rwanda's projected image, and concluded that Rwanda needs more accurate marketing strategy; Gao Jing (2014) conducted a research on the differentiation of Hangzhou tourism destination brands through questionnaire survey. Xiao Liang (2009) based on tourism websites of Chinese Mainland and Taiwan study the tourist destination image of Taiwan.

In summary, there is a growing literature on tourist destination image (Yan, Q., Zhou, S., \& Wu, S., 2018), and the method of unstructured methods for measuring destination image has been recognized by the academic community. However, existing studies neglected the difference between official projected image and tourists' perceived image. From the perspective of the comparison, this paper explored whether there are differences between perceived and projected image in small tourism town, and draw conclusions for future marketing strategies.

\section{$3 \quad$ Methodology}

This study comparatively analyzed textual data produced by destination marketing organizations and by destination visitors who post their travel reviews on websites or OTA, such as Ctrip. Beijing Wtown was used as a case study destination for this empirical research. Beijing Wtown is a comprehensive destination including sightseeing, leisure, vacation, business exhibition and so on. It is one of the representatives of small tourism town in China. The main analytical approach employed in this study was comparative content analysis.

The research process is divided into three steps. The first step is to select samples. The fist sample is user-generated content (UGC) on the internet, widely considered a rich data source that reflects consumer experiences and evaluation of products, which consists of a random sample of 72 online travel reviews, published on Mafengwo.com, Ctrip.com and Lvmama.com in Chinese by tourists who visited Beijing Wtown during 2016-2018. The second sample is promotional text reflecting projected image of Beijing Wtown, including the introduction of Beijing Wtown on the official website and Wechat, news reports and presentations on OTA. The second step is to build a dictionary of word breakers, which is the basis of content analysis. The word segmentation dictionary of this paper is based on the actual situation of tourism in Beijing Wtown and the image recognition category of tourism destination. The third step is 
analysising samples by the ROST Content Mining, a commonly used software for content analysis supports the study of the most-used keywords, cluster, sentiment, traffic and etc.

Table 1. The frequency of the most-used keywords of sample 1.

\begin{tabular}{lll|lll|lll}
\hline No. & Words & Frequency & No. & Words & Frequency & No. & Words & Frequency \\
\hline 1 & Beijing Wtown & 827 & 18 & Check in & 68 & 35 & Convenient & 45 \\
2 & Great Wall & 289 & 19 & Parking Lot & 68 & 36 & Noctivagation & 44 \\
3 & Hotel & 228 & 20 & Unique & 67 & 37 & Line up & 43 \\
4 & Viewpoint & 222 & 21 & Room & 67 & 38 & Free & 42 \\
5 & SPA & 153 & 22 & View of Night & 66 & 39 & Homestay & 41 \\
6 & Beijing & 134 & 23 & Restaurant & 57 & 40 & Photograph & 40 \\
7 & Simatai Great Wall & 130 & 24 & Attraction & 53 & 41 & Breakfast & 38 \\
8 & Guesthouse & 116 & 25 & Snack & 52 & 42 & Tour & 37 \\
9 & Night & 99 & 26 & Mi Yun & 50 & 43 & Jiang Nan & 37 \\
10 & Ticket & 86 & 27 & Accommodation & 47 & 44 & Friend & 36 \\
11 & Kids & 77 & 28 & Light & 47 & 45 & Style & 36 \\
12 & Church & 75 & 29 & Comfortable & 47 & 46 & Flavour & 36 \\
13 & Tourist & 74 & 30 & North & 46 & 47 & Weekend & 35 \\
14 & Experience & 73 & 31 & Building & 46 & 48 & Sima Baked Roll & 33 \\
15 & Show & 72 & 32 & Cable Car & 46 & 49 & Expressway & 33 \\
16 & Gu Bei & 69 & 33 & Travel & 45 & 50 & Square & 33 \\
17 & Service & 68 & 34 & Luggage & 45 & & & \\
\hline
\end{tabular}

Table 2. The frequency of the most-used keywords of sample 2.

\begin{tabular}{llllll|lll}
\hline No. & Words & Frequency & No. & Words & Frequency & No. & Words & Frequency \\
\hline 1 & Beijing Wtown & 510 & 18 & Homestay & 37 & 35 & Food & 21 \\
2 & Great Wall & 235 & 19 & Security & 35 & 36 & Characteristic & 21 \\
3 & Viewpoint & 115 & 20 & Christ & 33 & 37 & Country Landscape & 21 \\
4 & Travel & 114 & 21 & History & 32 & 38 & View of Night & 21 \\
5 & Beijing & 95 & 22 & Service & 32 & 39 & Building & 21 \\
6 & Simatai Great Wall & 89 & 23 & Star & 31 & 40 & Light & 21 \\
7 & SPA & 81 & 24 & Facility & 31 & 41 & Guesthouse & 21 \\
8 & Tourist & 78 & 25 & Tour & 29 & 42 & Resort & 20 \\
9 & Experience & 72 & 26 & Night & 28 & 43 & Fair & 20 \\
10 & North & 69 & 27 & Enjoy & 27 & 44 & Kids & 20 \\
11 & Culture & 64 & 28 & Way of Life & 26 & 45 & The Republic of China & 20 \\
12 & Vacation & 63 & 29 & Leisure & 25 & 46 & Jiang Nan & 19 \\
13 & Mi Yun & 56 & 30 & Traditonal & 24 & 47 & Show & 19 \\
14 & Wuzhen & 49 & 31 & Nature & 22 & 48 & Scenery & 19 \\
15 & Hotel & 48 & 32 & Good & 22 & 49 & Friend & 18 \\
16 & Unique & 46 & 33 & Style & 22 & 50 & Restaurant & 17 \\
17 & Tradition & 39 & 34 & Admire & 22 & & & \\
\hline
\end{tabular}

\section{Comparative Analysis of Perceived and Projected Image of Beijing}

\section{Wtown}

\subsection{Contrastive Analysis of the Most-used Keywords}

By importing two samples into ROST Content Mining in TXT format for word frequency analysis, and eliminating words such as "Yes" and "Simplified" that are not related to the research, get two lists of the most-used keywords (Table 1, Table 2), ranking based on the number of appearance. 
Table 3. The conclude of tourist perceived and market projected image.

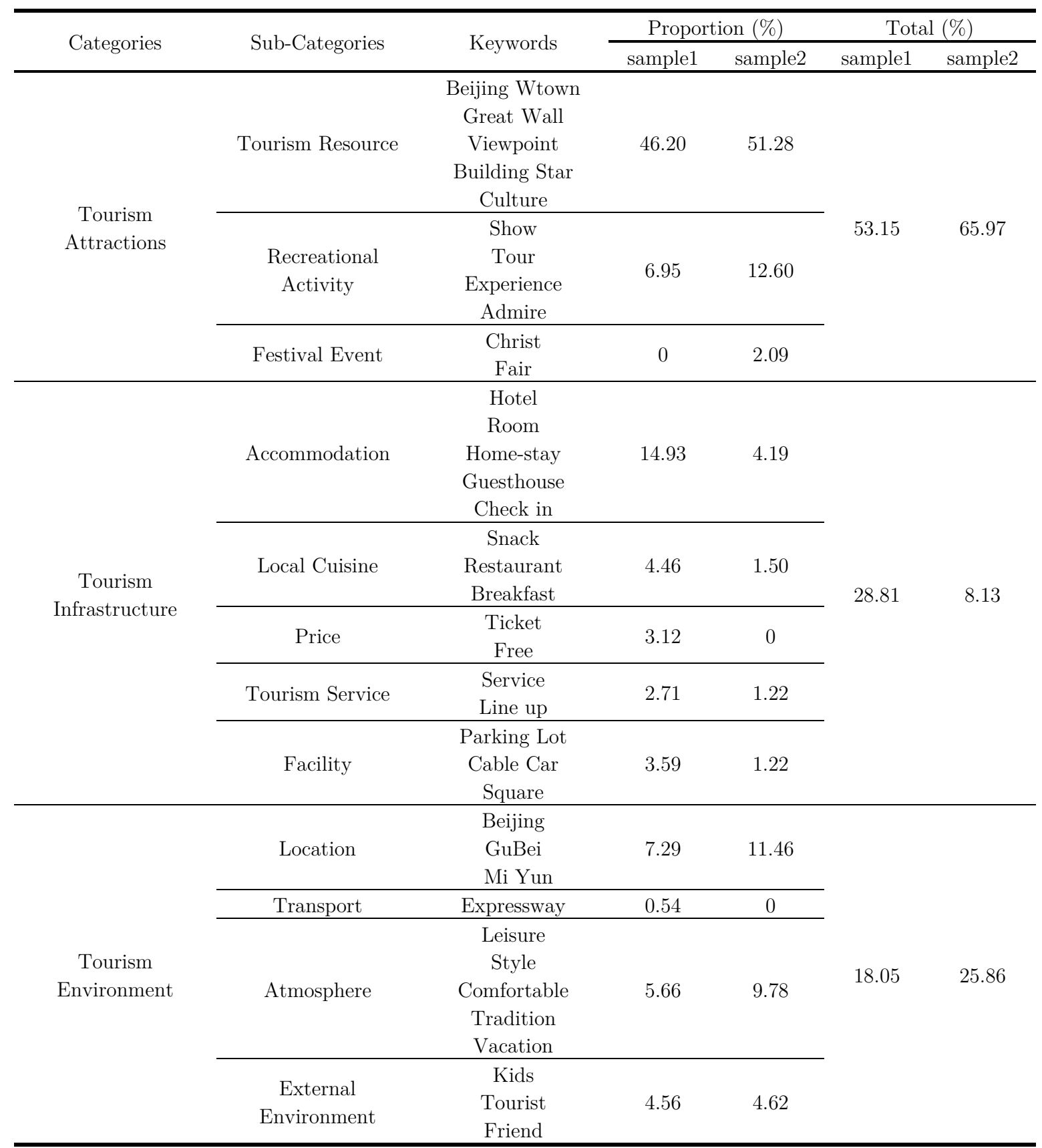

By comparing the most-used keywords of two samples, reflecting perceived and projected image, two important conclusions are drawn. Firstly, the tourist destination image of Beijing Wtown includes three main themes. Combining with the first 50 most-used keywords extracted from samples and the system of restructuring tourist destination perception structure proposed by Zhong Quna (2015), the tourist destination image of Beijing Wtown can be roughly classified into three themes: tourist attractions, such as resources, entertainment and festival events; tourism infrastructure, such as hotel, catering and services; tourism environment, such as transportation, public services and local atmosphere. Secondly, perceived image is more specific. Comparing the most-used keywords of the samples, firstly, it is found that the perceived image of the main attractions of Beijing Wtown is the same as that of projected image, such as Beijing Wtown, Viewpoint, and Great Wall. Moreover, tourists also perceived other specific attractions such as Church and Sima Baked Roll. Secondly, in the supporting reception facilities, the tourists' 
perception of hotel accommodation is specific, such as Room, Check in, Luggage, Breakfast, while the official projected image only includes Hotel, Homestay. In terms of tourism environment atmosphere, the official projection has more vocabulary, such as Wuzhen, Characteristics, Leisure, Jiangnan, the Republic of China and so on, while there are fewer words related to the environment in travel reviews. Overall, official projected texts are more likely to create a good atmosphere of Beijing Wtown through lots of words related to environment, while the perceived image by tourists are more specific.

\subsection{Analysis the Tourist Destination Image of Beijing Wtown}

In order to understand the tourists' perceived and projected image of Beijing Wtown in depth, this paper classifies and summarizes the most-used keywords into three main categories and 12 sub-categories, each of which accounts for the proportion shown in Table 3.

According to Table 3, firstly, among the three main categories of tourist destination image, the most-used keywords related to tourism attractions occupies a larger proportion, accounted for $53.15 \%$ ( perceived image) and $65.97 \%$ ( projected image), respectively, both exceeding $50 \%$. This shows that tourists who visited Beijing Wtown have a strong perception of tourism attractions, and marketing organizations of Beijing Wtown pay more attention to the publicity of attractions. Secondly, tourism infrastructures are closely related to tourists' activities. Tourists' perception of tourism infrastructure $(28.82 \%)$ is higher than that tourism environment $(18.05 \%)$, while marketing organizations of Beijing Wtown ignore the publicity of tourism supporting facilities, only accounted for $8.13 \%$. On the whole, the proportion of tourist attractions is much higher than the other two categories, which indicates the imbalance between perceived image by tourists and the projected image by destination marketing organizations.

In terms of tourism attractions, tourists' perception of tourism resources is obviously stronger than entertainment activities and festival events, indicating that tourists are not sufficiently engaged in tourism in Beijing Wtown, and they still mainly rely on the way of sightseeing to know Beijing Wtown. Furthermore, tourists' perception of tourism resources, entertainment activities and festival events are lower than the market projections. It is obvious that the town's marketing organizations not achieved the desired of tourism activity.

In terms of tourism infrastructure, tourists are more concerned with the setting of supporting facilities than marketing organizations, especially the perception of accommodation. While visitors' attention to accommodation-related facilities and experiences accounted for $14.93 \%$, the mentioned about these two aspects in samples reflecting projected image is only $4.19 \%$. Tourists' attention of food and beverage, travel prices and services is also slightly higher than the market. In general, tourists have obvious perceptions of tourism supporting facilities, but operators don't pay enough attention to this.

In terms of tourism environment, in general, compared with the other two categories, the difference between the perception of tourists and market launch of the environment is the smallest, only $7 \%$. However, this is a certain gap in local environment and atmosphere. It shows that the local environment and atmosphere created by the town and perceived by the visitors have certain deviations.

\subsection{A Comparative Analysis of the Semantic Network of Beijing Wtown}

It further recognizes the association and meaning of text vocabulary, and then realizes the perceived and projected tourist destination image of Beijing Wtown. ROST Content Mining software is used to analyze the two samples. Semantic network analysis can visually deconstruct the relationship between words and words and the semantic path between network text content syntax and concept (Peng Hongsong, Lu Lin, Lu Xingfu, et al,2014), thus visually reflecting the relationship between high-frequency words and the closeness of connections. The closer the word is to the word and the denser the line, the higher the collinear frequency and the greater the degree of association. The analysis results as shown in Figure 1 and Figure 2.

Firstly, by comparing the semantic network of two types of samples, it is obvious that the high-frequency words of semantic network of sample 1 is more than the semantic network of sample 2, indicating that the tourists' perceptions are more abundant, and the official texts are more concentrated. Secondly, both the semantic network of sample 1 and sample show a hierarchy. The former core layer contains the vocabulary of Beijing Wtown, the Great Wall, hotels, viewpoints, Simatai Great Wall and 
Beijing. The latter core layer contains the vocabulary of Beijing Wtown, the Great Wall, Beijing, Simatai Great Wall, vacation, viewpoint and experience. This shows that destination marketing organizations tend to make use of the resources of the town and the geographical location for shaping the tourist destination image. Combined with the most-used keywords of sample 2, Beijing Wtown is marketed a resort located in Beijing, relying on ancient town and the Great Wall. And the tourists' perception of Beijing Wtown can be summarized as a scenic spot in Beijing that relies on the resources of ancient town, the Great Wall and SPA to provide accommodation and services.

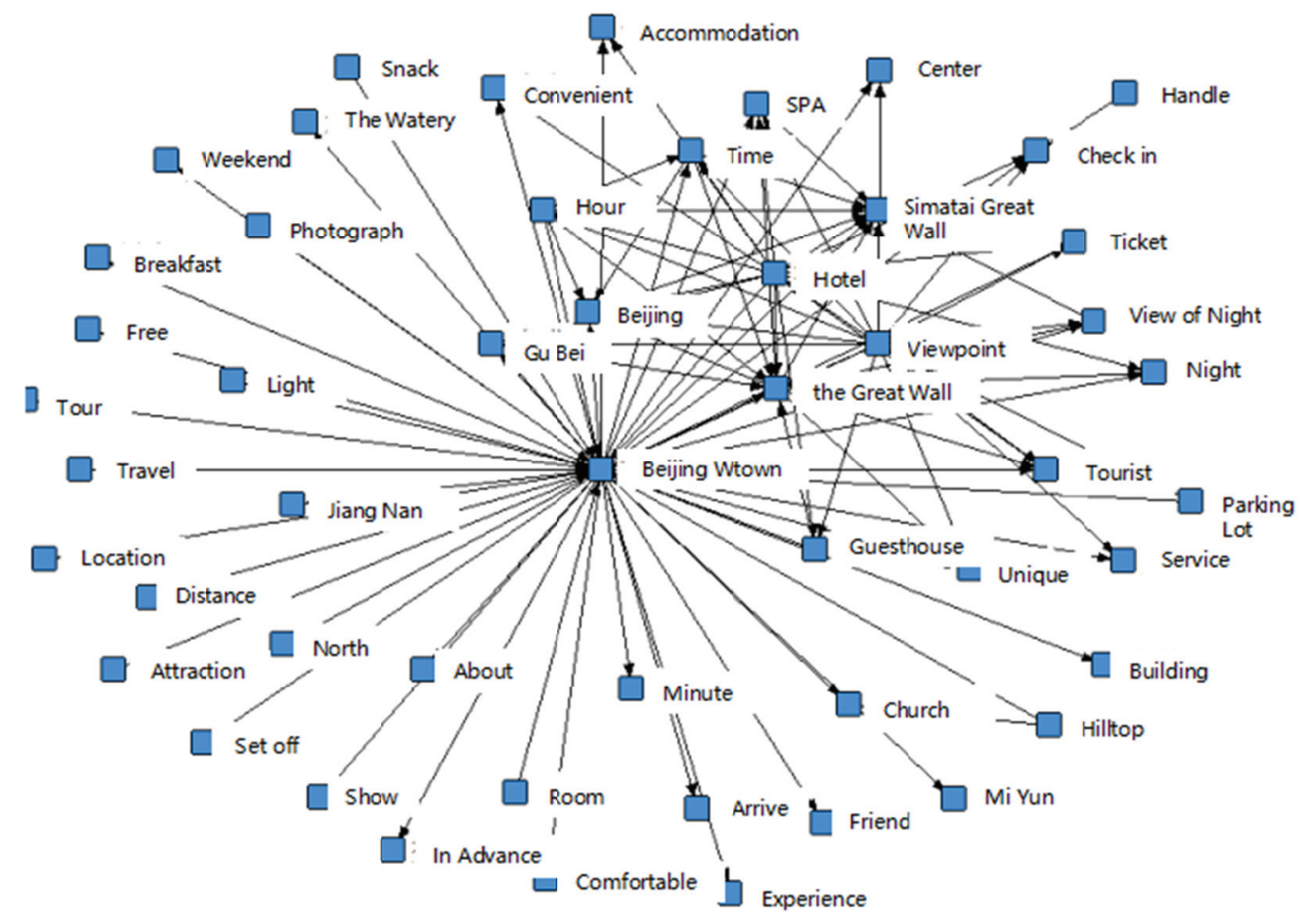

Figure 1. Semantic Network of Sample 1.

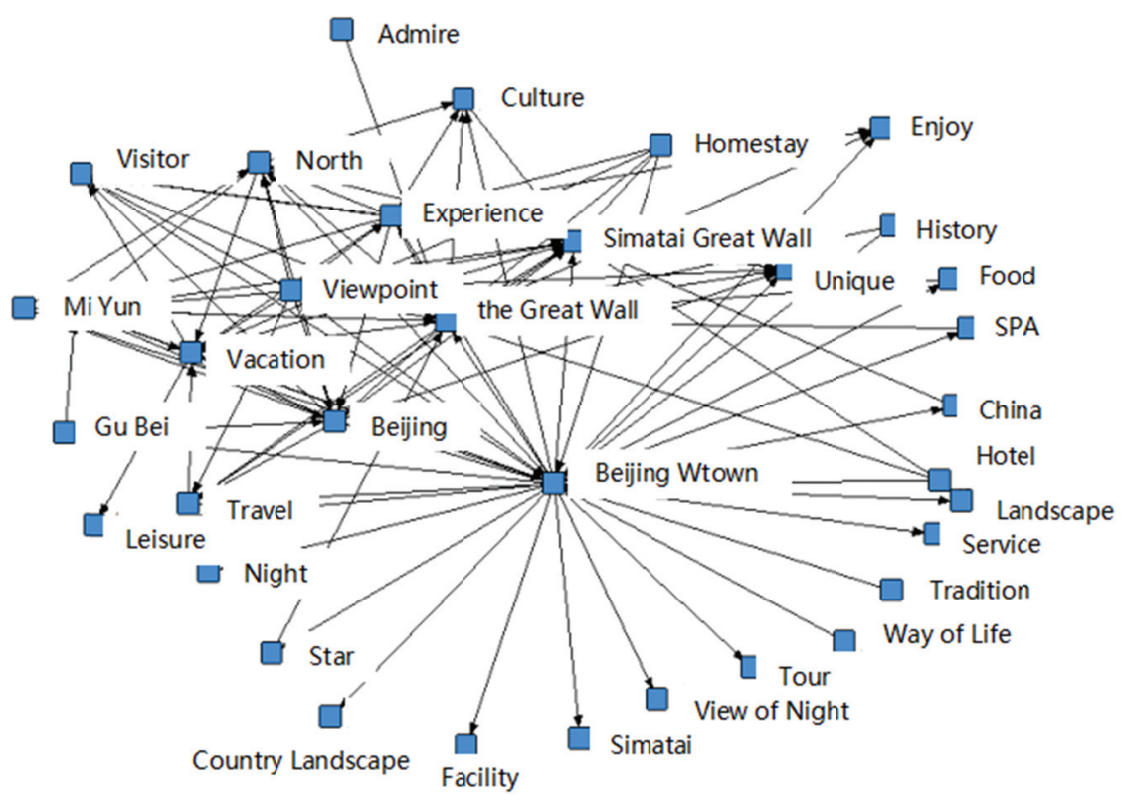

Figure 2. Semantic Network of Sample 2. 


\section{$5 \quad$ Conclusions and Suggestions}

\subsection{Conclusions}

The tourist destination image of Beijing Wtown can be summarized into three main categories and 12 sub-categories. Both perceived and projected image can be roughly divided into three categories and 12 sub-categories: tourism attractions (resource, activity and festival event), tourism infrastructure (hotel accommodation, catering, tourism service and facility), tourism environment (environment, traffic, public service and local atmosphere).

Unbalanced tourist destination image of Beijing Wtown. This paper divides the tourist destination image into three main themes. It can be seen from Table 2 that the proportion of tourism attractions is significantly higher than the other two themes in perceived and projected image. In addition, tourists' perception of tourism environment is at a lower level. This phenomenon may be caused by insufficient publicity of tourism infrastructure by operators. In summary, the tourist destination image of Beijing Wtown is unbalanced.

There are differences between perceived and projected tourist destination image of Beijing Wtown. Firstly, according to the semantic network, the official intention is to shape the image of the resort, while the tourists' perception of the characteristics of vacation is not obvious, which indicate that there is a certain deviation in the overall image. Secondly, there are certain deviations in the three major themes, which are mainly reflected in the tourists' perception of tourist attractions and local atmosphere is weaker than the market delivery image, and the perception of the tourism supporting facilities is stronger than that.

\section{$5.2 \quad$ Suggestions}

Attach importance to the construction and publicity of tourism facilities. Visitors' perception of infrastructure is weak, indicating that existing infrastructure does not meet the needs of visitors. In order to cope with this, the town should invest more funds to speed up the construction of facilities. In addition, tourists are more concerned about accommodation and food, so the operators should strengthen the promotion of supporting facilities and improve the competitiveness of the town.

Face up to the differences in tourist destination image. Through the research of this paper, there is a certain difference between the projected and the perceived image of Beijing Wtown. These differences may be due to the inconsistency between the propaganda and construction of the scenic spot, or the perception of tourists lags behind the propaganda of the scenic spot. The town should actively adjust the marketing strategy or construction plan, so that tourists can obtain the expected tourism experience.

Enrich activities for improving the experience of tourists. In the perception of tourist attractions, tourists have little perception of tourism activities, which shows that tourists are less involved in activities in scenic spots. As the tourism industry develops, tourists are paying more and more attention to the interaction and experience in the process of travel. Therefore, in addition to Christmas theme event, the operators of Beijing Wtown can also develop some folk activities and festivals according to the cultural resources of the Great Wall and the ancient town, so that visitors can deeply participate and interact in any time.

\section{References}

1. Zhao Hua. Analysis on the innovation and exploration of the tourist characteristic town[J]. On Economic Problems,2017(12):104-107.

2. Yang Liguo, Liu Qiang, LI Qiang. The maturation and its evaluation system of tourism town: A case study of Hunan customs and cultural tourism town[J]. Economic Geography,2017,37(07):191-197.

3. Chon, K.-S.. The role of destination image in tourism: A review and discussion[J]. Tourist Review,1990,45(02):2-9.

4. Li, J., Ali, F., \& Kim, W. G.. Reexamination of the role of destination image in tourism: An updated literature review[J]. E-Review of Tourism Research,2015,12(03):191-209. 
5. Wu Xiaogen, Du Yingying. Empirical study on perceptive image formation of tourists on tourist destination: A case study of Nantong, Jiangsu Province[J]. Geographical Research,2011,30(09):1554-1565.

6. Pike, S.Destination image analysis-a review of 142 papers from 1973 to 2000[J]. Tourism Management, 2002,23(5):541-549.

7. Zang Dexia, Huang Jie. Review of overseas studies on destination image: Based on the article of tourism management and annals of tourism research in the last decade[J]. Tourism Science,2007(06):12-19.

8. Echtner, C. M., \& Ritchie, J. R. B. The meaning and measurement of destination image[J]. Journal of Tourism Studies,1991,2(2):2-12.

9. Liu Huan. The comparative study between the perceived image and the projected image of Chinese tourism image[D].Shandong University,2015.

10. Michael Grosspietsch. Perceived and Projected image of Rwanda: Visitor and Intentional Tour Operator Perspectives[J]. Tourism Management,2006,(27):225-234.

11. Gao Jing, Jiao Yongbing. Differentiating brand positioning of tourism destinations: A brand personality perspective[J]. Tourism Tribune,2014,29(03):49-57.

12. Xiao Liang, Zhao Liming. The tourism destination image of Taiwan disseminated on Internet--Based on a content analysis of travel related websites across Taiwan straits[J]. Tourism Tribune,2009,24(03):75-81.

13. Yan, Q., Zhou, S., \& Wu, S..The influences of tourists' emotions on the selection of electronic word of mouth platforms[J]. Tourism Management,2018,66:348-363.

14. Zhong Lina. A reconstruction of destination' perception structure based on the context and complex network analysis[J]. Tourism Tribune,2015,30(08):88-95.

15. Peng Hongsong, Lu Lin, Lu Xingfu, et al. The network structure of cross- border tourism flow based on the social network method: A case of Lugu Lake region[J]. Scientia Geographica Sinica,2014,34(9):1041-1050. 